\title{
Gadd $45 \alpha$ activity is the principal effector of Shigella mitochondria-dependent epithelial cell death in vitro and ex vivo
}

\author{
L Lembo-Fazio ${ }^{1}$, G Nigro ${ }^{1,7}$, G Noël ${ }^{1}$, G Rossi ${ }^{2}$, F Chiara ${ }^{3,4}$, K Tsilingiri $^{5}$, M Rescigno ${ }^{5}$, A Rasola ${ }^{3}$ and ML Bernardini ${ }^{\star, 1,6}$
}

Modulation of death is a pathogen strategy to establish residence and promote survival in host cells and tissues. Shigella spp. are human pathogens that invade colonic mucosa, where they provoke lesions caused by their ability to manipulate the host cell responses. Shigella spp. induce various types of cell death in different cell populations. However, they are equally able to protect host cells from death. Here, we have investigated on the molecular mechanisms and cell effectors governing the balance between survival and death in epithelial cells infected with Shigella. To explore these aspects, we have exploited both, the HeLa cell invasion assay and a novel ex vivo human colon organ culture model of infection that mimics natural conditions of shigellosis. Our results definitely show that Shigella induces a rapid intrinsic apoptosis of infected cells, via mitochondrial depolarization and the ensuing caspase-9 activation. Moreover, for the first time we identify the eukaryotic stress-response factor growth arrest and DNA damage $45 \alpha$ as a key player in the induction of the apoptotic process elicited by Shigella in epithelial cells, revealing an unexplored role of this molecule in the course of infections sustained by invasive pathogens.

Cell Death and Disease (2011) 2, e122; doi:10.1038/cddis.2011.4; published online 24 February 2011

Subject Category: Immunity

In the course of a bacterial infection, complex molecular interplays occur between host cells and bacteria. To eradicate or contain the infection, myeloid cells activate strategies aimed at destroying the pathogen, whereas epithelial cells are committed to reduce the bacterial loading. This can be achieved by the suicide of infected cells, mainly through activation of programmed cell death (PCD) or of the autophagic process. ${ }^{1}$ Conversely, pathogens deal with the need to establish a replicative niche in the host and to assure their own survival. This can be obtained by inducing apoptosis or pyroptosis in the host cell; ${ }^{1}$ however, bacteria can also protect the infected cells from PCD or provoke necrosis or, finally, interfere with the autophagic process. ${ }^{2}$ Notably, the possibility exists that these mechanisms are not mutually exclusive, and that the choice among them depends on several factors, including the kinetics and route of infection, the cell population infected, and on the specific pathogen.

This complexity of regulatory mechanisms is observed in the invasive process of Shigella spp., an enteric pathogen that causes bacillary dysentery in humans. ${ }^{3}$ The pathogenicity of Shigella resides on the ability to invade the colonic mucosa through secreted effectors that allow these bacteria to penetrate epithelial cells, to escape from the phagocytic vacuole and to disseminate throughout the epithelium. ${ }^{4,5}$
In epithelial cells, Shigella activates NF- $\kappa \mathrm{B}$ via peptidoglycan sensing by the pattern recognition receptor Nod1, ${ }^{6}$ thereby triggering the secretion of CXCL8. This event initiates the inflammatory cascade that is the hallmark of shigellosis in the colonic mucosa. These pathogens induce cell death in macrophages mainly through a 'NLCR4 inflammasome'- and caspase-1-mediated pyroptosis ${ }^{7}$ accompanied by the subsequent release of IL-1 $\beta$ and IL-18 that exacerbates the severity of inflammation. ${ }^{7,8}$ Others studies reported that Shigella is equally able to kill macrophages through necrosis, oncosis and a caspase-9-mediated apoptosis. ${ }^{9-11}$ Furthermore, in fibroblasts Shigella infection provokes necrotic cell death through a pathway dependent on the host oxidative stress responses. ${ }^{12}$ However, mechanisms of cell death tuning by Shigella are more complex than a simple induction of death. In fact, Shigella-infected HeLa cells can be partially protected from staurosporine (STP)-induced apoptosis, ${ }^{13}$ or undergo to massive caspase-9-mediated apoptosis on lysis of these pathogens resident in host cell cytoplasm. ${ }^{14}$

Therefore, a picture emerges in which both inhibition and induction of different forms of cell death can coexist during cell infection by Shigella. The prevalent host cell response could be determined by the cell type, the multiplicity of infection (MOI), that is, the number of the invading bacteria, the

\footnotetext{
${ }^{1}$ Dipartimento di Biologia e Biotecnologie 'Charles Darwin', Sapienza-Università di Roma, Roma, Italy; ${ }^{2}$ Dipartimento di Scienze Veterinarie,Università degli Studi di Camerino, Matelica (Macerata), Italy; ${ }^{3}$ Dipartimento di Scienze Biomediche, Università degli Studi di Padova, Padova, Italy; ${ }^{4}$ Dipartimento di Medicina Ambientale e Sanità Pubblica, Università degli Studi di Padova, Padova, Italy; ${ }^{5}$ Department of Experimental Oncology European Institute of Oncology, Milan, Italy and ${ }^{6}$ Istituto Pasteur-Fondazione Cenci Bolognetti, Sapienza-Università di Roma, Roma, Italy

${ }^{*}$ Corresponding author: ML Bernardini, Dipartimento di Biologia e Biotecnologie 'Charles Darwin', Istituto Pasteur-Fondazione Cenci Bolognetti, Sapienza-Università di Roma, Via Dei Sardi 70, Rome 00185, Italy. Tel: + 396 49917850; Fax: + 396 49917594; E-mail: marialina.bernardini@ uniroma1.it

${ }^{7}$ Current Address: Institut Pasteur, Unité de Pathogénie Microbienne Moléculaire, 75724 Paris Cedex 15, France.

Keywords: apoptosis; mitochondria; Shigella; infection; Gadd45 $\alpha$

Abbreviations: MOI, multiplicity of infection; EVOC, ex vivo human organe culture; PCD, programmed cell death; GADD45 $\alpha$, growth arrest and DNA damage $45 \alpha$; $\mathrm{CHX}$, cycloheximide; TNF- $\alpha$, tumor necrosis factor- $\alpha$; STP, staurosporine; TMRM, tetramethylrhodamine methyl ester

Received 18.10.10; revised 28.12.10; accepted 10.1.11; Edited by RA Knight
} 
presence of autocrine/paracrine effectors, the occurrence of stress reactions and by other not yet identified factors.

The purpose of this study is to further investigate on the host regulatory circuits that regulate the balance between death and survival in epithelial cells infected by Shigella. By using HeLa cells as an epithelial cell model system, we have analyzed: (i) the impact of the number of intracellular bacteria on the equilibrium of life/death; (ii) the type of cell death elicited by Shigella infection, focusing on the involvement of mitochondria and caspases in this process; and (iii) the pro- and anti-apoptotic transcriptome.

To assess whether the results obtained in HeLa cells mirror in vivo epithelial responses, we purposely developed a novel ex vivo model of Shigella infection of a human colonic mucosa. Finally, by exploiting these two experimental models, we identified the role of the stress sensor growth arrest and DNA damage $45 \alpha$ (Gadd45 $\alpha$ ) as a main host cell player in triggering the death of the cells infected by Shigella.

\section{Results}

HeLa cells infected with Shigella undergo a dosedependent apoptosis. To examine the influence of the $\mathrm{MOI}$ on host cell death, we infected HeLa cells with S. flexneri wild-type strain M90T at MOI 10, 50 and 100 during a period of incubation (p.i.) of $5 \mathrm{~h}$. The number of intracellular bacteria per cell increased rapidly at MOI 100, whereas it was significantly lower at $\mathrm{MOI} 10$ and 50 (Figure 1a), as previously reported. ${ }^{15}$

Infected cells underwent apoptosis in a time- and MOI-dependent fashion, as shown by the number of both TUNEL- and annexin V-positive cells (Figures $1 \mathrm{~b}$ and $\mathrm{c}$ and Supplementary Figure S1); especially, at $5 \mathrm{~h}$ p.i. $34 \%$ of the cells resulted positive to TUNEL analysis, while at this same time point, around 19 and $6 \%$ of the cells were positive at $\mathrm{MOI}$ of 50 and 10, respectively. These data strongly indicated that death of the infected cells is dependent on the number of intracellular bacteria. When HeLa cells were exposed to the noninvasive variant of M90T, BS176, we did not detect any apoptosis induction even after $12 \mathrm{~h}$ of infection (Supplementary Figures S2A and $\mathrm{C}$ ), indicating that the death of HeLa cells was strictly dependent on the intracellular residence of bacteria.

Shigella infection triggered caspase-3 activation in a time- and $\mathrm{MOl}$-dependent manner (Figure 2A) matching the kinetics and the degree of annexin- $\mathrm{V}$ positivity and cell death (compare Figures $2 \mathrm{~A}$ and $1 \mathrm{~b}$; Supplementary Figure S1). At $\mathrm{MOI}$ of 100 , starting from $3 \mathrm{~h}$ p.i. caspase-3 was significantly fourfold higher with respect to the control uninfected cells. At $5 \mathrm{~h}$ p.i., this value was of about 3.7-fold and 6-fold over the controls at MOI of 50 and 100, respectively (Figure 2A). The noninvasive strain BS176 did not elicit any caspase-3 activation at any time analyzed (Supplementary Figure S2B).

In order to assess the activity of apical caspases, we infected HeLa cells with wild-type strain M90T at a MOI 100. Both caspase- 8 and caspase- 9 were already activated at $1 \mathrm{~h}$ p.i. with a similar kinetics and degree (Figures $2 \mathrm{~B}$ and $\mathrm{C}$ : compare with the positive controls STP and cycloheximide
$(\mathrm{CHX})$ /tumor necrosis factor (TNF)- $\alpha$, respectively). Fluorescence studies performed by using the binding of fluorescentcoupled peptides inhibitors to the activated forms of caspase-9 (FLICA-caspase-9 (FAM-LEHD-FMK)) and caspase-8 (FLICA-caspase-8 (FAM-LETD-FMK)) confirmed that epithelial cells infected with M90T, transformed with DsRed plasmid vector, triggered the activation of both initiator caspases (Figures 2D and E).

To understand the relative role played by each of the two apical caspases in caspase- 3 activation, previously determined by luminometric assay, we carried out a dual strategy. First, we assessed whether Shigella infection induced an early mitochondrial depolarization, which triggers caspase-9mediated activation of caspase-3 in intrinsic apoptotic pathway. Other groups have already reported mitochondrial dysfunction on Shigella infection of fibroblasts. ${ }^{12,16}$ Accordingly, by using flow cytometry analysis we found that about one-third of the infected cells displayed depolarized mitochondria as early as $1 \mathrm{~h}$ p.i. (Figures $3 a$ and b). In addition, we observed that, starting from the first hour of infection, a fraction of cells undergoing mitochondrial membrane depolarization also displayed the caspase- 3 activation, as assayed by the binding of the fluorescent-coupled DEVD inhibitor to the activated form of caspase-3 (FLICA caspase-3 (FAM-DEVDFMK)). Second, we exploited an RNAi strategy in order to silence either caspase-8 or caspase- 9 . We observed that the caspase-3 activity was significantly reduced in the presence of RNAi for caspase-9, that is, $1.7 \pm 0.19$ versus $3.9 \pm 0.05$ at $3 \mathrm{~h}$ of incubation p.i. and $1.4 \pm 0.3$ versus $6 \pm 0.19$ following $5 \mathrm{~h}$ of incubation p.i. (Figure $3 \mathrm{c}$ ). We did not observe any difference in caspase-3 values in the presence of RNAi for caspase-8 (Figure $3 d$ ), suggesting that an early caspase-8 activation is not necessary to induce apoptosis following Shigella infection, whereas the intrinsic apoptotic pathway is responsible for effector caspase activation.

Apoptotic and anti-apoptotic circuits activated during Shigella invasion. To understand the mechanisms of apoptosis regulation by Shigella, we analyzed the apoptosis transcriptome of HeLa cells infected with M90T at MOI 100 at 1,3 and $5 \mathrm{~h}$ of incubation p.i.

We used an oligonucleotide array spotted with 135 apoptotic and anti-apoptotic genes (see Materials and methods section) and identified a panel of genes differentially expressed, which were subjected to hierarchical clustering to reveal expression trends (Figure $4 a$ and Supplementary Table S1).

The expression profile was similar at the three time points examined with a small subset of genes differentially expressed under these three conditions of infection (see Supplementary Table S1). Hierarchical clustering identified three main categories of gene transcripts. The first group, which includes the majority of analyzed transcripts, was downregulated at the three time points with respect to the noninfected HeLa cells (e.g., bik or bcl2). In the second group, we classed the genes downregulated at $1 \mathrm{~h}$ and upregulated at 3 and $5 \mathrm{~h}$ (e.g., jun or $b c / X_{L}$ ); finally, the third group encompasses the genes permanently activated with a sustained upregulation (e.g., gadd $45 \alpha$ or bad). 


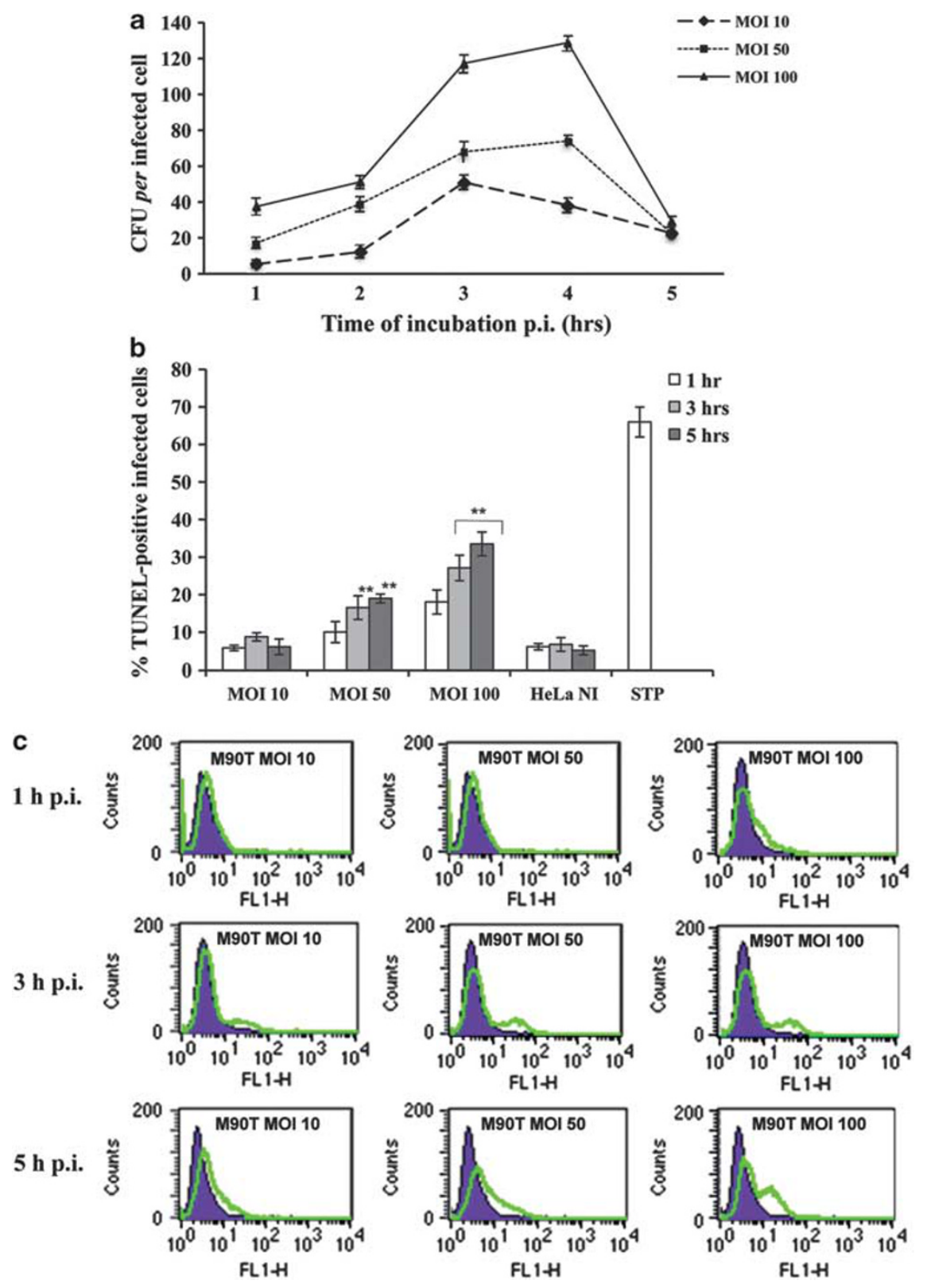

Figure 1 Intracellular growth kinetics of $S$ flexneri M90T in HeLa cell monolayers and host cell death. (a) Kinetics of intracellular bacterial growth of the invasive $S$. flexneri strain M90T during $5 \mathrm{~h}$ of incubation p.i. at MOI 10, 50 and 100; (b) TUNEL assay on HeLa cells infected with Shigella as above. HeLa NI, non-infected HeLa cells; STP, noninfected HeLa cells treated for $4 \mathrm{~h}$ with STP $(2 \mu \mathrm{M})$. (c) A representative cytofluorimetric output of TUNEL analysis performed at $1 \mathrm{~h}$ (upper panel), $3 \mathrm{~h}$ (middle panel) and $5 \mathrm{~h}$ of incubation p.i. (lower panel). Tunel-positive (i.e., dead) cells display an increased FITC staining (green line in the graph). In (a and $\mathbf{b}$ ), bars represent the mean values \pm S.D. from five independent experiments. ${ }^{*} P<0.01$ after Student's $t$-test

Down- or upregulation of a representative number of mRNAs was verified by quantitative real-time PCR (Figure 4b), confirming in the majority of cases the same trend of regulation shown by microarray analysis (e.g., bad, bax, bcl2, bclX $X_{L}, n f-\kappa b 1$, gadd45 $)$. However, the level of regulation of some of these transcripts, such as akt2, bik, birc2 (IAP-1) and birc3 (IAP-2) was deeply underestimated by the microarray study (compare Figure $4 \mathrm{~b}$ and Supplementary Table S1). The modulation of Akt, IAP-1 and IAP-2 proteins could dramatically influence the balance between survival and apoptosis during Shigella infection, as all these proteins display a potent survival activity at different steps of the apoptotic cascade. Therefore, we verified whether the transcriptional upregulation of mRNA for Akt2, IAP-1 and IAP-2 was matched by a corresponding increase in their protein level. As reported in Figure 4c, we found that the Akt protein level strongly increased from $1 \mathrm{~h}$ p.i., while that of IAP-1/2 raised especially at $3 \mathrm{~h}$ p.i. We then assessed the modulation of anti- and pro-apoptotic proteins of the $\mathrm{Bcl}-2$ family. We found a complex pattern of regulation (Figure 4d): induction of both pro-apoptotic (Bad) and antiapoptotic $\left(\mathrm{Bcl}-\mathrm{X}_{\mathrm{L}}\right)$ proteins, but also repression of the 
A

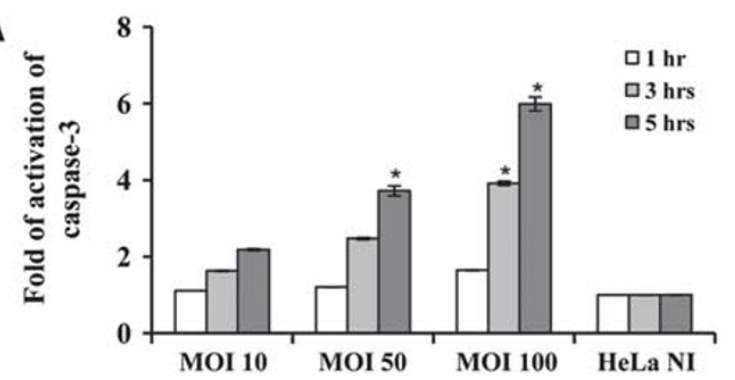

B

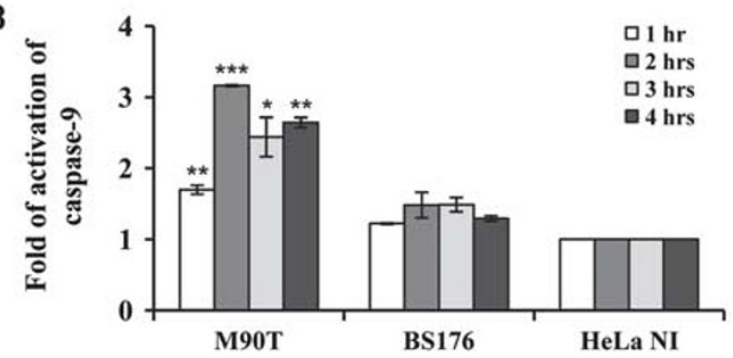

C

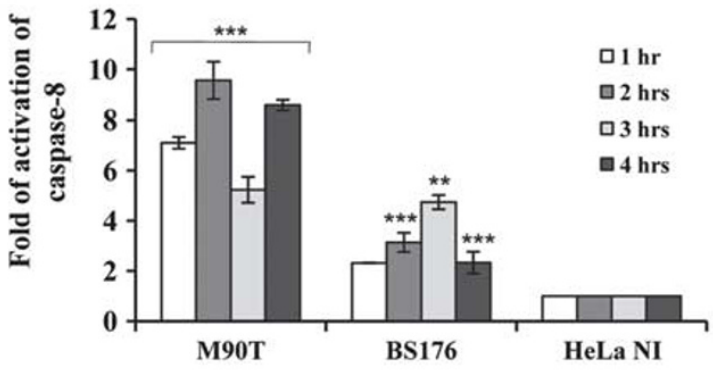

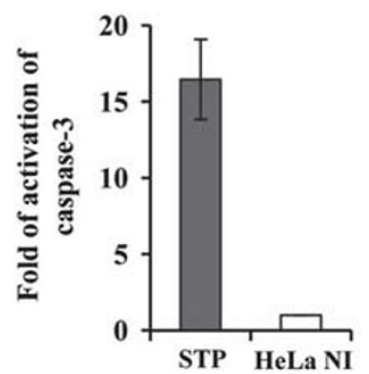
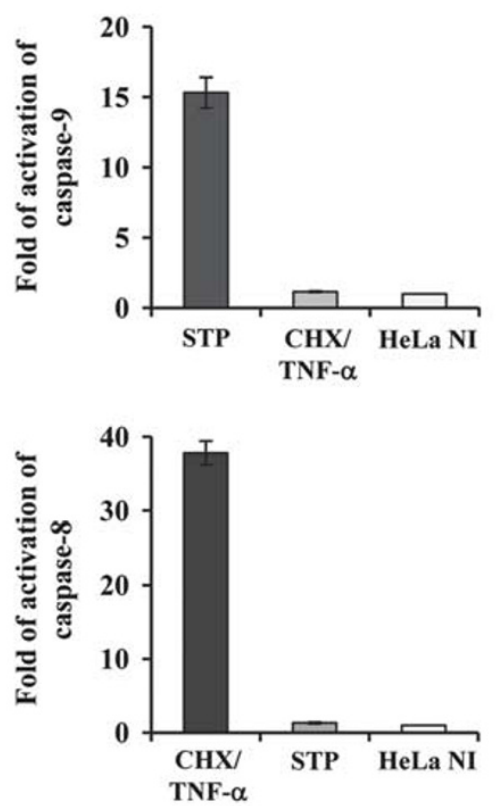

D

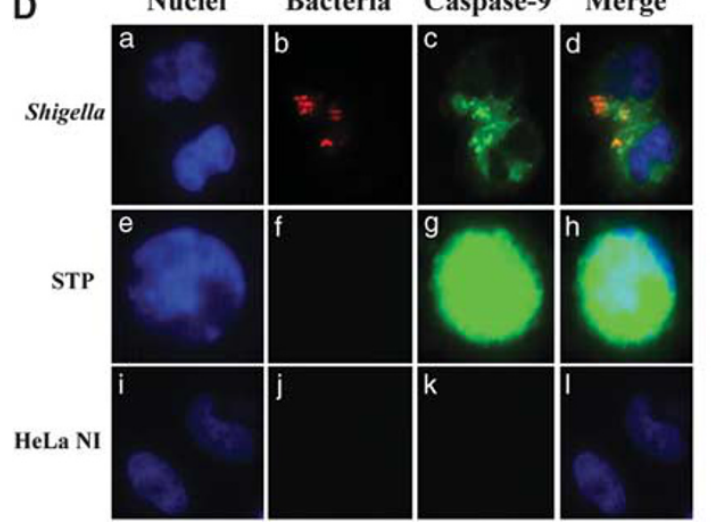

E

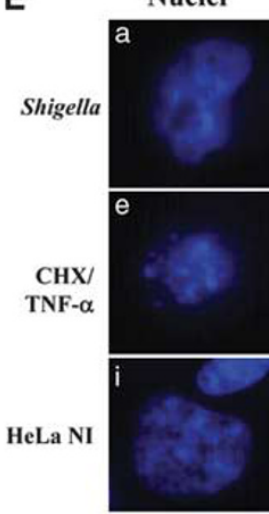

Bacteria

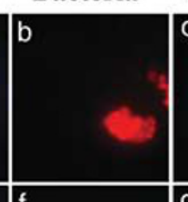

Caspase-8

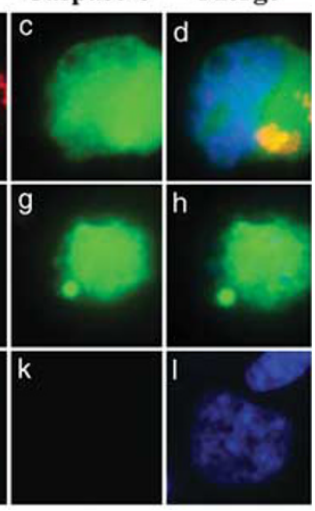

Figure 2 Caspase activation in HeLa cells infected with Shigella. (A) Kinetics of caspase-3 activation following infection of HeLa cells with M90T at different MOls as above. (B) Caspase-9 and (C) caspase-8 activity in HeLa cells infected with M90T and its noninvasive variant BS176 (MOI of 100) at the reported time points. HeLa cells treated for $4 \mathrm{~h}$ with STP $(2 \mu \mathrm{M})$ or with $\mathrm{CHX}(10 \mu \mathrm{g} / \mathrm{ml})$ plus TNF- $\alpha(100 \mathrm{ng} / \mathrm{ml})$ for $12 \mathrm{~h}$ were used as a control of caspase- $9 / 3$ and caspase- 8 activation, respectively. HeLa NI, non-infected HeLa cells. Report assay data correspond to the mean \pm S.D. (triplicate determinations) and are representative of three independent luminometric assays. ${ }^{\star} P<0.05,{ }^{* \star} P<0.01,{ }^{* * *} P<0.001$ after Student's $t$-test. (D and $\left.\mathbf{E}\right)$ Immunofluorescence analysis of caspase-9 (D) and caspase-8 (E) maturation in HeLa cells infected with M90T-DsRed (MOI 100) at $2 \mathrm{~h}$ of incubation p.i. (a, b, c, d panels) Treated with STP or CHX plus TNF- $\alpha$, as above (e, f, $g, h$ panels in $\mathbf{D}$ and $\mathbf{E}$, respectively) and uninfected (i, j, k, I panels). Cells were processed for labeling with fluorescent-coupled LEHD inhibitor to the activated form of caspase-9 (FLICA caspase-9 (FAM-LEHD-FMK)) or fluorescent-coupled LETD inhibitor to the activated form of caspase-8 (FLICA caspase-8 (FAM-LETD-FMK)) and DAPI. Shigellae, expressing DsRed plasmid vector, are stained in red. Magnification: $\times 40$

death-inducing Bax and of the pro-survival Bcl-2. Altogether, these results suggest that modulation of the levels of Bcl-2 family members is not a primary event in apoptosis induction by Shigella infection. In accordance with both microarray and qPCR data, we found that the protein amount of Gadd $45 \alpha$, a protein describes as acting as a pro-apoptotic 

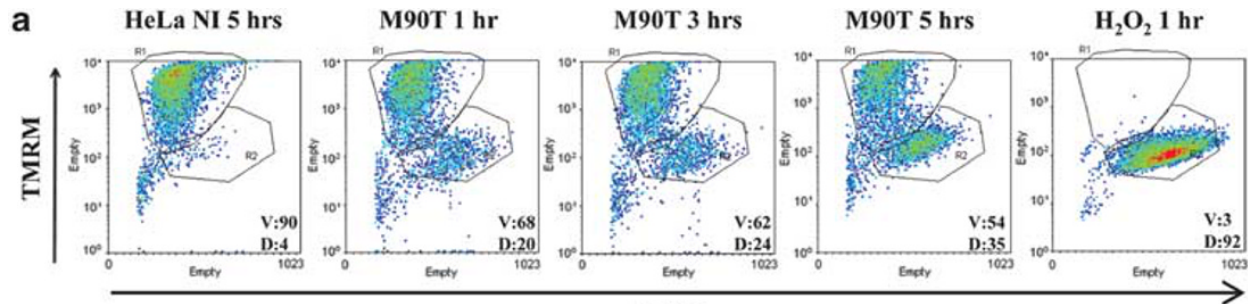

FSC

b
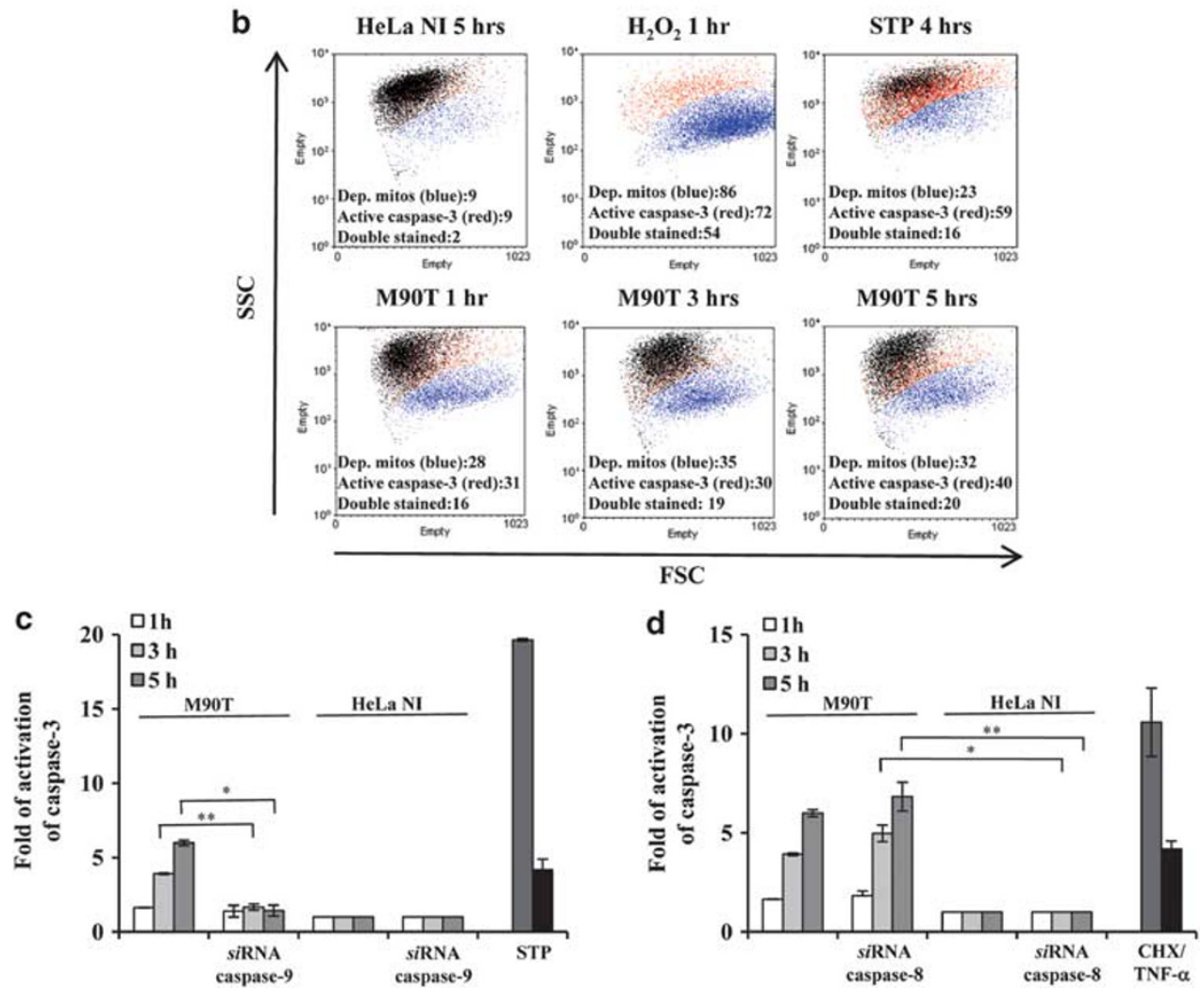

Figure 3 Shigella-infected HeLa cells undergo intrinsic apoptosis. (a) FACS analysis (forward scatter, FSC, versus TMRM) showing mitochondrial depolarization. The percentages of viable cells (V, TMRM positive, in the R1 quadrant) and of depolarized cells (D, TMRM negative, in the R2 quadrant) are reported. (b) FACS analysis of mitochondrial potential (TMRM staining; blue population) and of caspase-3 activation (FLICA caspase-3 labeling; red population). Both populations were determined on diagrams FSC versus fluorophore, and are shown together on a FSC versus SSC plot. In (a and b), HeLa cells were infected with M90T (MOI 100) for the reported time points; treatment with $\mathrm{H}_{2} \mathrm{O}_{2}(5 \mathrm{mM}$ for $1 \mathrm{~h})$ and with STP as in Figure 2 were used as positive controls of mitochondrial depolarization and of caspase activation. Cells transiently transfected with sRNA for caspase-9 (c) or for caspase-8 (d) were infected with M90T at MOI 100 and caspase-3 activity was measured at the reported time points. HeLa cells treated for $4 \mathrm{~h}$ with STP or with CHX plus TNF- $\alpha$ as specified in Figure 2 were used as a control. HeLa NI, non-infected HeLa cells. Report assay data correspond to the mean \pm S.D. (triplicate determinations) and are representative of five independent luminometric assays. ${ }^{\star} P<0.05,{ }^{* \star} P<0.01,{ }^{* \star *} P<0.001$ after Student's $t$-test

player, ${ }^{17}$ was significantly upregulated during infection (Figure 4d).

Involvement of Gadd45 $\alpha$ in Shigella-mediated cell death. Gadd $45 \alpha$ is a stress-inducible gene regulated by a variety of genotoxic and non-genotoxic stresses. Gadd $45 \alpha$ may have an important role as both a pro-apoptotic ${ }^{17-19}$ and pro-survival factor as well. ${ }^{20}$ Given the sustained upregulation of Gadd $45 \alpha$ in infected HeLa cells, we asked whether and to which extent Gadd $45 \alpha$ could be involved in Shigella-mediated apoptosis. We analyzed caspase-9, -8 and -3 activity and DNA fragmentation in HeLa cells depleted of Gadd $45 \alpha$ through RNAi and infected with M90T as above.
Uninfected cells or cells transfected with scramble siRNA and infected as above were used as controls. We found that caspase- 9 maturation was dramatically abrogated in the presence of RNAi for Gadd $45 \alpha$, starting from $1 \mathrm{~h}$ of incubation p.i. (Figure $5 B$ ), while caspase-8 activity remained unaltered (Figure 5A).

In accordance with data of caspase-9 inhibition, HeLa cells expressing Gadd $45 \alpha$ siRNA and infected with M90T displayed a strong decrease in caspase-3 activity (Figure $5 \mathrm{C}$ ) and a significant reduction of DNA fragmentation (Figures $5 \mathrm{E}$ and F). We therefore investigated whether the lack of Gadd $45 \alpha$ could affect caspase-3 activation following STP treatment that engages the intrinsic apoptotic pathway as Shigella does. 


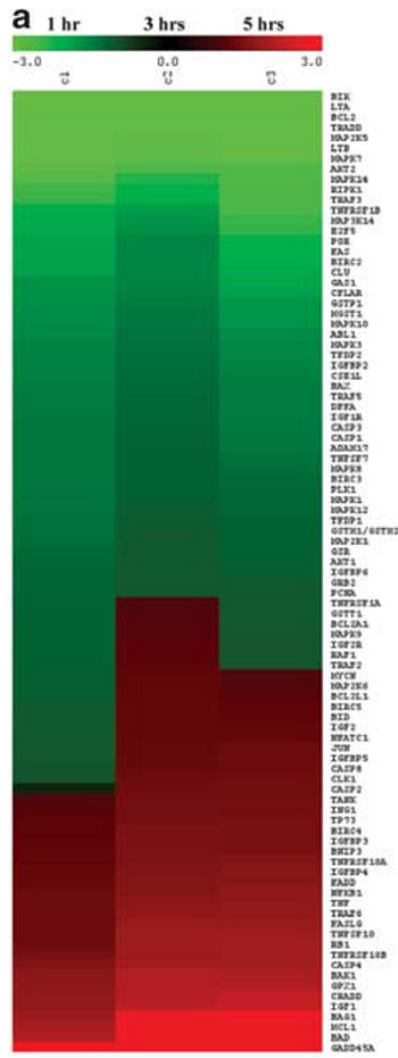

b

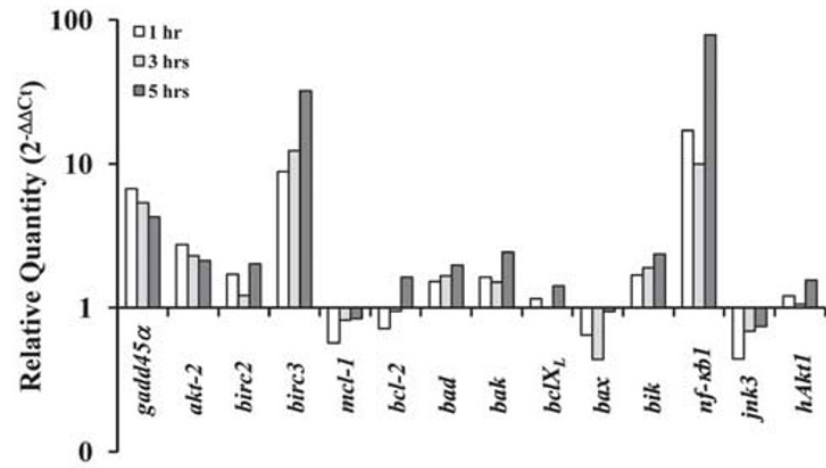

C

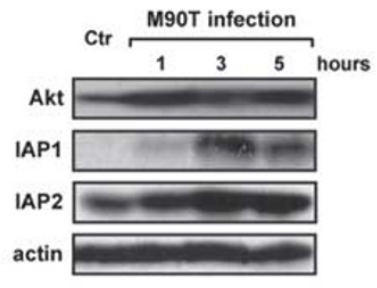

d

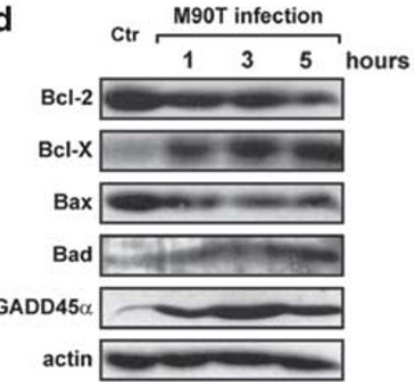

Figure 4 Modulation of pro- and anti-apoptotic gene expression in HeLa cells on infection with S. flexneri M90T. (a) Transcriptional profile of pro- and anti-apoptotic genes expressed by HeLa cells infected with S. flexneri M90T (MOI 100) at 1, 3 and $5 \mathrm{~h}$ of incubation p.i. Red and green colors represent up- and downregulation of gene expression, respectively, as compared with uninfected cells. The key for intensity of expression is indicated under the bar. (b) Validation/determination through qPCR for a representative subset of genes whose expression is highly modulated by Shigella infection. Results are normalized to the internal gapdh gene control and are presented on a logarithmic scale as the ratio of gene expression between infected and uninfected HeLa cells. (c and d) Western immunoblot analysis of changes in protein expression levels of HeLa cells following Shigella infection. Cell lysis was carried out at the reported time points. Blots were probed with actin as a loading control

As expected, Gadd45 $\alpha$-interfered HeLa cells treated with STP showed low level of caspase-3 values (Figure 5D) while no significant changes in caspase-3 activity was recorded in cells treated with $\mathrm{CHX}$ plus TNF- $\alpha$, confirming that Gadd $45 \alpha$ is mainly involved in the mitochondrial pathway of apoptosis.

Shigella-mediated epithelial cell apoptosis in an ex vivo human colon organ culture (EVOC) model of infection. Not many animal systems have proven to be reliable models of Shigella infection. To overcome this limitation, we exploited here a recently developed technique allowing us to mimic as much as possible the human conditions. The three-dimensional architecture present in the EVOC guarantees the maintenance of physical parameters fundamental for several functions of the cells, such as spatial orientation and impact of gravity.

Therefore, human colonic specimens were apically infected with $10^{8} \mathrm{CFU}$ of M90T or BS176 and incubated overnight $(\mathrm{ON})$. After this time, the samples were treated for histopathological and immunohistochemical $(\mathrm{IH})$ analysis.

To determine the impact of Shigella on epithelial cell survival in the organotypic culture, we analyzed the morphological changes through hematoxylin/eosin (HE) staining. As shown in Figure 6B (panel a), the mucosa architecture of the uninfected samples remained unaltered and only scattered inflammatory cells were interspersed throughout the chorion.

In tissue sections infected with M90T, the epithelial layer was fully disorganized showing severe degeneration and death areas (Figure 6B, panel b). Indeed, an abundant inflammatory infiltrate organized in a pseudo-follicular structure was also evident. In contrast, tissues infected with BS176 did not display any significant alteration of the epithelium (Figure 6B, panel C).

Cells containing shigellae were highlighted by immunolabeling the bacterial lipopolysaccharyde (LPS). Intensity of LPS presence was scored as previously described ${ }^{21}$ and reported in Figure 6A. As expected, no immunolabeling was noticed in uninfected sample (Figure 6B, panel d) while in the M90T-infected sections an intense intra- and extra-cellular immunostaining was present in the epithelial layer or free in mucus that covers the epithelium (Figure 6B, panel e). With BS176, LPS-immunostaining was mainly concentrated into the mucus, in accordance with the noninvasive phenotype of this strain (Figure 6B, panel f).

In serial sections of the colonic tissue, $\mathrm{IH}$ analysis of caspase-3 maturation evidenced that in uninfected colonic mucosa only rare positive cells (located in the epithelium and 
A
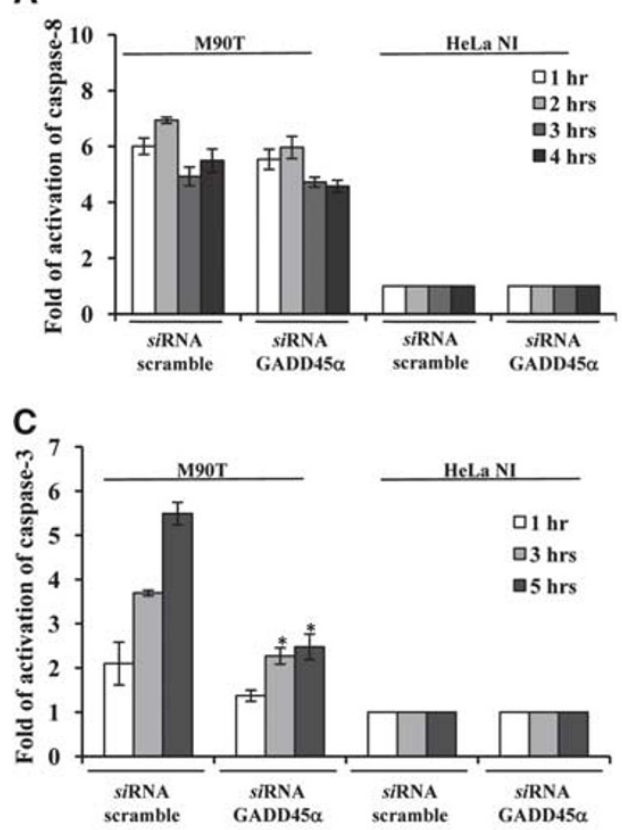

E

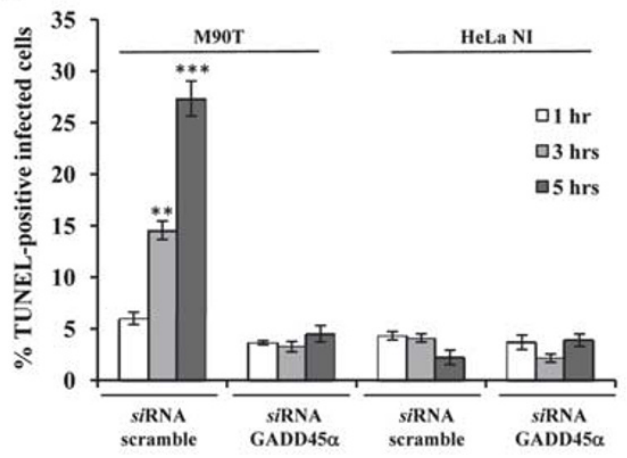

B

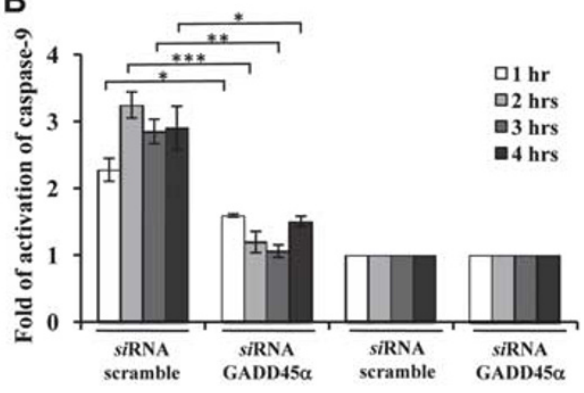

D
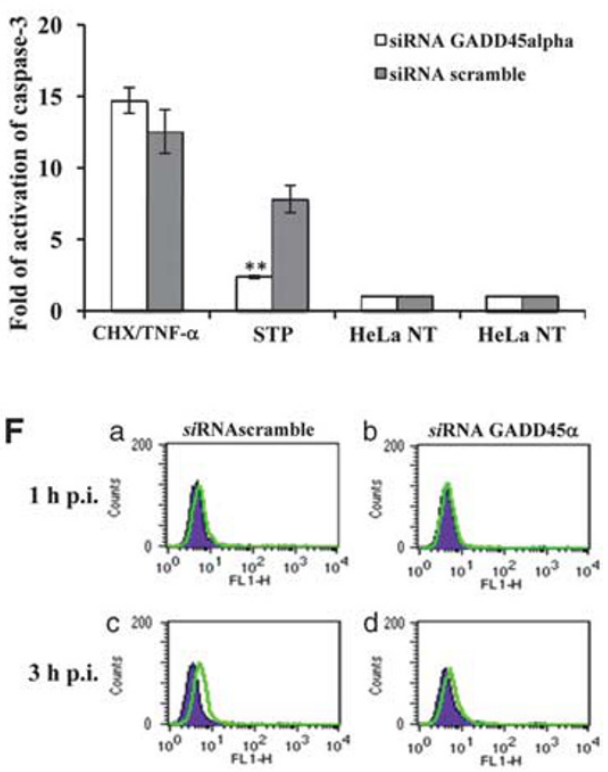

5 h p.i. 要

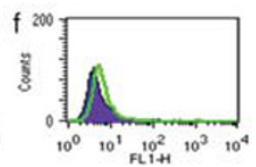

Figure 5 Gadd45 $\alpha$ triggers Shigella-mediated apoptotic cell death in infected HeLa cells. Activity of caspase-8 (A), caspase-9 (B) and caspase-3 (C), and TUNEL assay ( $E$ and $\mathbf{F}$ ) on HeLa cells transiently transfected with a Gadd45 $\alpha$ or a scramble sRNA. Cells were infected with M90T at MOI of 100 for the reported time points. HeLa cells treated with STP or with CHX plus TNF- $\alpha$, as detailed in Figure 2, were used as a control (D). HeLa Nl, non-infected HeLa cells. Report assay data correspond to the mean \pm S.D. (triplicate determinations) and are representative of three independent luminometric assays. ${ }^{\star} P<0.05,{ }^{* \star} P<0.01,{ }^{* \star *} P<0.001$ after Student's $t$-test. (F) A representative cytofluorimetric output of TUNEL analysis performed at $1 \mathrm{~h}$ (upper panel, a and b), $3 \mathrm{~h}$ (middle panel, $\mathrm{c}$ and d) and $5 \mathrm{~h}$ of incubation p.i. (lower panel, e and f)

chorion) were present (Figures $6 \mathrm{~A}$ and $\mathrm{B}$, panel g). With M90T, extensive areas of epithelial cells and some cells throughout the inflammatory infiltrate resulted marked by caspase-3 immunostaining (Figures $6 \mathrm{~A}$ and $\mathrm{B}$, panel $\mathrm{h}$ ). Mucosa infected with BS176 showed a pattern of caspase-3 labeling similar to the uninfected cells (Figure 6B, panel i).

In the same histological sections, uninfected or infected by Shigella, the expression of Gadd $45 \alpha$ was restricted mainly to the epithelial layer (Figure 6B, panels j, k, I). A strong immunostaining was evident in cells infected with M90T (Figures 6A and B, panel k), in which a colocalization of Gadd $45 \alpha$ and LPS was also observed (data not shown). Moreover, Gadd $45 \alpha$ immunolabeling retraced the distribution observed with caspase-3 staining (compare panels $\mathrm{h}$ with k). Notably, Gadd $45 \alpha$ upregulation was not found in mesenchimal or in mononuclear cells (i.e., lympho-monocytes or plasma cells) of mucosal chorion; this observation is in accordance with the analysis performed by different authors in lungs where Gadd $45 \alpha$ expression is restricted to the airway epithelium and type II pneumocytes, also in the presence of phlogosis characterized by inflammatory infiltrate or BALT activation. $^{22}$

Finally, a constant colocalization of Gadd $45 \alpha$, cleaved caspase-3 and TUNEL nuclear-positive reaction was observed in stained serial sections of M90T-infected tissues (Figure 6B, panels $h, k$ and $n$ ).

In contrast to these observations, control (Figure 6B, panel $\mathrm{m}$ ) and BS176-infected samples (panel o) showed mild surface disarray, scarce colonocyte apoptosis and relative preservation of surface and crypt architecture, associated 
with rare co-expression of Gadd $45 \alpha$ and a TUNEL-positive reaction.

We may conclude that the use of this novel polarized ex vivo organ culture system highlights that Shigella-induced epithelial cell apoptosis is associated with Gadd $45 \alpha$ upregulation.

\section{Discussion}

In this study, we demonstrate that Shigella invasion of epithelial cells: (i) regulates the expression of a complex pool of pro- and anti-apoptotic genes; (ii) induces a rapid apoptosis, mainly via caspase- 9 activation and mitochondrial
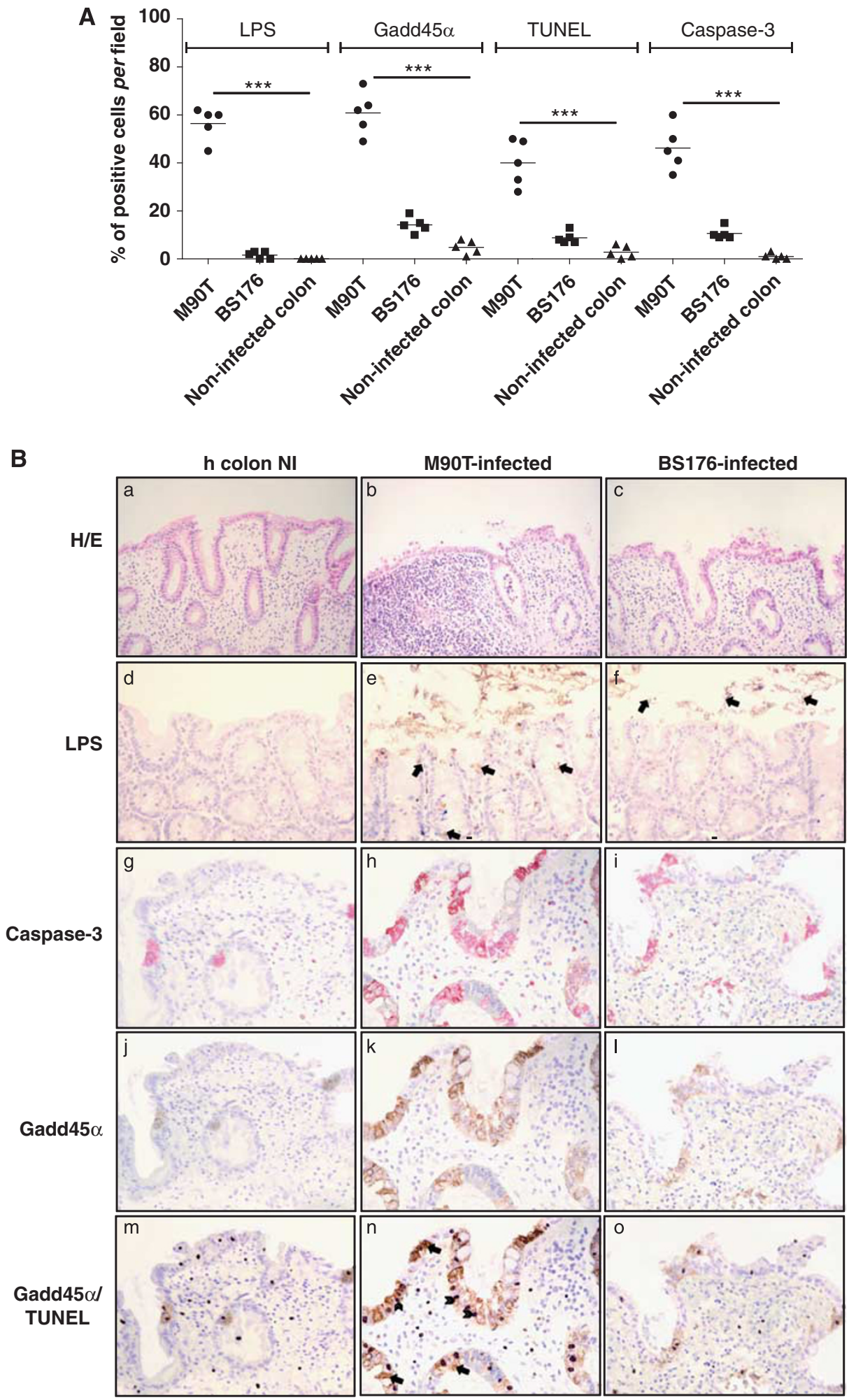
involvement; and (iii) activates the pro-apoptotic factor Gadd $45 \alpha$, which in turn has a key role in the execution of the apoptotic process.

Different groups have tackled the issue of death regulation on Shigella infection of non-myeloid cells. Results have often been puzzling, as both cell death induction (either apoptotic or necrotic) or inhibition have been reported. ${ }^{12,13}$ These diverse observations reflect the complexity of host cell responses to Shigella invasion. In this view, changes of experimental parameters such as target cell type (MEF versus HeLa cells), $\mathrm{MOI}$, time of infection (from 1 to $24 \mathrm{~h}$ ), effective number of intracellular bacteria and the use of exogenous adhesion systems (e.g., AFA E, E. coli afimbrial adhesin), could well account for the heterogeneity of reported results.

Indeed, our results are in agreement with this complexity of responses, as we observe regulation of both pro- and antiapoptotic proteins. Several pathogens, including Legionella and Chlamydia, induce the expression of pro-survival genes to maximize their persistence in host cells. ${ }^{23}$ We found that infection with Shigella elicits the expression of several potent pro-survival factors, such as C-IAP-1, C-IAP-2, Akt and Bcl-X Both IAP proteins and Akt interfere through a variety of mechanisms with apoptotic pathways ${ }^{24,25}$ and were reported to be upregulated or activated on Shigella infection. ${ }^{26,27}$ In the case of $\mathrm{Bcl}-\mathrm{X}_{\mathrm{L}}$, its anti-apoptotic activity is balanced on the mitochondrial surface by multiple interactions with both antiand pro-apoptotic Bcl-2 family members. ${ }^{28}$ We observed a complex response endowed with inhibition of the pro-survival $\mathrm{Bcl}-2$ and of the apoptogenic Bax, and with induction of Bad, another pro-apoptotic family member. Thus, we can envision a scenario characterized by the simultaneous activation of apoptotic and anti-apoptotic pathways, whose balance is finely modulated during infection with Shigella toward the eventual commitment to death of the infected cell.

As for the type of cell death prompted by Shigella invasion, both Dupont et al. ${ }^{16}$ and Carneiro et al. ${ }^{12}$ report ROS production and mitochondrial membrane depolarization following a 5-8-h infection at MOI 100 of MEFs. Both groups conclude that Shigella causes necrotic cell death in the MEF model. Our results agree with these observations, in that we have observed both ROS production (data not shown) and mitochondrial depolarization in infected HeLa cells, and these events are detectable as early as $1 \mathrm{~h}$ p.i. at MOI 50 (see Figures $3 a$ and $b$ ). However, it must be highlighted that, even if mitochondrial membrane depolarization constitutes a point of no return in cell death induction, accounting for ROS production and respiratory arrest, release of $\mathrm{Ca}^{2+}$, pyridine nucleotides and of a pool of apoptogenic proteins, ${ }^{29}$ it can be upstream to either necrosis or apoptosis, depending on a wide set of variables, such as the bioenergetic status of the cell, ${ }^{30-32}$ the intensity of the noxious stimulus or the availability of a functioning apoptotic machinery. ${ }^{33}$ When apoptosis occurs downstream to mitochondrial depolarization, this is specifically hallmarked by activation of caspases.

In line with this issue, we demonstrate activation of both initiator and effector caspases, TUNEL positivity and phosphatidylserine exposure on the host cell surface. We also show caspase-3 activation and TUNEL positivity in epithelial cells infected with Shigella in EVOC model, emphasizing the importance of apoptosis induction following infection of epithelial cells.

Notably, during Shigella infection, a fraction of HeLa cells undergoing mitochondrial depolarization also displays caspase activation (double stained cells in Figure $3 \mathrm{~b}$ ), demonstrating that mitochondrial damage occurs in apoptotic cells. Another fraction of cells is endowed with mitochondrial depolarization, but without any detectable caspase activity (the blue population in Figure $3 \mathrm{~b}$ ). These could be either cells entering the apoptotic process, upstream to caspase induction or necrotic cells, in accord with Dupont and Carneiro. It is possible that at a higher $\mathrm{MOI}$, the proportion of necrotic cells could increase even in our experimental model, as stress conditions might be too intense for the set-up of the apoptotic response (e.g., a massive mitochondrial depolarization could cause a rapid ATP depletion, making caspase activation impossible).

In accordance with a mitochondrial involvement in apoptosis induction, activation of the key effector caspase-3 is almost abolished by knocking-down caspase-9 (Figure 3c) but not caspase-8 (Figure 3d), despite its early activation at $1 \mathrm{~h}$ p.i. (Figure 2C). Notably, caspase-8 is also transiently induced by the noninvasive strain, which is unable to cause cell death. Altogether these observations indicate that caspase- 8 is rapidly activated by Shigella, possibly through interactions with membrane death receptors; but this activation is not required for a full-blown apoptotic process, which instead relies on a secondary induction of the intrinsic caspase-9-dependent pathway downstream to mitochondrial depolarization.

Furthermore, we found that induction of Gadd $45 \alpha$ is a main effector event in apoptosis triggering by Shigella. In fact, gadd $45 \alpha$ is strongly and rapidly induced in HeLa cells and its depletion dramatically reduces Shigella-induced apoptosis. Both caspase-9/3 activation (Figures 5B and C) and TUNEL positivity are abrogated by Gadd $45 \alpha$ knock-down, whereas caspase- 8 induction is not affected, indicating that the intrinsic branch of apoptosis induction is specifically affected by the Gadd $45 \alpha$ absence. Consistently, in EVOC model gadd $45 \alpha$ is strongly induced in cells displaying caspase-3 activation and TUNEL positivity (Figures $6 \mathrm{~A}$ and $\mathrm{B}$ ) although this activation

Figure 6 Apoptosis assessment and Gadd45 $\alpha$ expression in a human ex vivo organ culture (EVOC) invasion assay with S. flexneri M90T. (A) Dot blot of the distribution of LPS, Gadd45 $\alpha$, TUNEL and caspase-3 immunostained epithelial cells in sections of human colon biopsies infected with M90T or BS176 (12h) or uninfected. Immunohistochemically stained cells were counted at $\times 400$ magnification. For each sample, five view fields in five sections were considered for cell enumeration. Circles represent the mean values per sample while the horizontal line represents the mean value per sample category. ${ }^{* *} P<0.001$ after Student's $t$-test. (B) Histopathological and IH characterization of human colon sections infected with M90T or BS176 or uninfected. Upper panels (HE and LPS): HE (a, b, c) HE staining; LPS (d, e, f): IH staining of $S$. flexneri 5 LPS, in e and $f$ bacterial LPS are indicated by arrows. In HE original magnification 200 ; in LPS original magnification $\times 400$. Lower panels: analysis in serial sections of EVOC of immunolabeled mature caspase-3 $(\mathrm{g}, \mathrm{h}, \mathrm{i})$, Gadd4 $4 \alpha(\mathrm{j}, \mathrm{k}, \mathrm{l})$ and colocalization of Gadd $45 \alpha$ immunostaining and positive TUNEL nuclei, Gadd45 $\alpha / T U N E L$ $(m, n, 0)$. All relevant informations are reported in the figure. Arrowheads indicate TUNEL-positive cells and arrows indicate cell positively immunostained by the Gadd45 $\alpha$ mAb. In caspase-3, Gadd45 $\alpha$ and Gadd45 $\alpha / T U N E L$ panels, original magnification $\times 400$. Human colon Nl: uninfected human colon; M90T-infected: EVOC infected overnight with $10^{8} \mathrm{CFU}$ of M90T; BS176-infected: EVOC infected over-night with $10^{8} \mathrm{CFU}$ of BS176 
does not involve a parallel modulation of p53 (data not shown).

Gadd45 $\alpha$ is known to be upregulated in response to a variety of cell stresses in order to elicit cell cycle arrest at the G2-M transition and to regulate the apoptotic response. ${ }^{17-19}$ Several studies highlight the pro-apoptotic role of Gadd $45 \alpha$ in different type of cells such as breast cancer cells, keratinocytes and HeLa. ${ }^{34,35}$ The mode of apoptosis induction by Gadd $45 \alpha$ is still debated, and could involve activation of the p38/JNK signaling pathways ${ }^{34}$ and/or activation of proapoptotic Bcl-2 family proteins. ${ }^{18}$ Consistently with this issue, we found that the pro-apoptotic Bcl2 family member Bad is upregulated and over-produced during Shigella infection. Moreover, the pro-survival pathway governed by the MAPKs could be impaired by the decreased expression of the genes encoding these proteins during infection. However, Gadd $45 \alpha$ protects from apoptosis hematopoietic cells exposed to genotoxic stress. ${ }^{34}$ In the framework of bacterial infection, it has been reported that challenge of oral epithelial cells with the invasive opportunistic pathogen Fusobacterium nucleatum induces Gadd $45 \alpha$ expression, while the noninvasive oral commensal Streptococcus gordonii does not. ${ }^{36}$ Consequently, these investigators propose that Gadd $45 \alpha$ could act as a stress sensor following bacterial invasion of epithelial cells, even if a mechanistic proof is still lacking.

Conclusively, we demonstrate for the first time that activation of Gadd $45 \alpha$ following bacterial invasion of epithelial cells is required for the building-up of the apoptotic response through activation of its intrinsic branch, which is the one responsible for Shigella-mediated cell death. Furthermore, the observation that Gadd $45 \alpha$ is activated in the colonic epithelial cells opens new perspectives in the study of factors influencing the outcome of pathogenesis of shigellosis.

\section{Materials and Methods \\ Bacterial strains, plasmids and growth conditions. The $S$. flexneri 5a strains used are M90T streptomycin-resistant $\left(\mathrm{Sm}^{\mathrm{R}}\right)$ and its noninvasive derivative BS176 (ref. 21). S. flexneri M90T-DsRed strain was created by transforming wild-type strain with DsRed plasmid vector (gently gifted by Maria Rescigno). The presence of DsRed plasmid vector did affect neither T3SS function, as demonstrated through effector proteins comassie blue staining or Shigella invasiveness, tested by the HeLa cell infection assay (data not shown). In addition to this, DsRed plasmid has no toxic effect on eukaryotic cells, as already reported. ${ }^{37}$ Bacteria were grown in Trypticase soy broth (BBL, Becton Dickinson and Co., Cockeysville, MD, USA) or agar (TSA). Streptomycin (Sm) and ampicillin (Ap) were added to cultures at $100 \mu \mathrm{g} / \mathrm{ml}$.}

Cell culture and infections. HeLa cells were maintained in D-MEM supplemented with $10 \%$ FBS (both by Cambrex BioScience, Walkersville, MD, USA). HeLa cell infections with invasive and noninvasive strains were performed as previously reported ${ }^{15}$ using the $\mathrm{MOI}$ of 10,50 and 100 . Incubation of cells and bacteria in the presence of gentamicin $(60 \mu \mathrm{g} / \mathrm{ml})$ was prolonged to $1,2,3,4$ or $5 \mathrm{~h}$, depending on the experiment. At desired time points of incubation, infected HeLa cells were processed to evaluate parameters associated with apoptosis. Intracellular multiplication of bacteria in HeLa cells was assayed as described previously. ${ }^{15}$

Cell death studies, caspases activity and annexin $\mathbf{V}$ staining. Apoptosis was assessed using TUNEL fluorometric (DeadEnd TUNEL fluorometric system, Promega, Milano, Italia) and annexin V staining (Annexin V-FITC Apoptosis Detection kit, BD Pharmingen, San José, CA, USA), according to the manufacturer's instructions. Both TUNEL and annexin $\mathrm{V}$ binding were analyzed using a flow cytometric analysis on a FACSCalibur cytometer (Becton Dickinson, San Josè, CA, USA). Data acquisition ( $10^{4}$ events for each sample) was performed using CellQuest software (Becton Dickinson, San Jose, CA, USA). Uninfected cells and cells treated for $4 \mathrm{~h}$ with $2 \mu \mathrm{M} \mathrm{STP}$, (Sigma Aldrich, Milano, Italia) were used in parallel. Cells deemed TUNEL or FITC-annexin V positive were those displaying fluorescence greater than the fluorescence of non-infected HeLa cells (control).

At desired time point of incubation post infection (p.i.), the activities of caspase-3, -8 and -9 were determined through a luminometric system by using Caspase Glo kit (Promega). Uninfected cells and cells treated for $4 \mathrm{~h}$ with $2 \mu \mathrm{M}$ STP or alternatively for $12 \mathrm{~h}$ with $\mathrm{CHX}(10 \mu \mathrm{g} / \mathrm{ml})$ (Sigma-Aldrich) plus TNF- $\alpha,(100 \mathrm{ng} / \mathrm{ml})$ (R\&D System, Minneapolis, MN, USA), were used as controls. Results are reported as fold induction of relative luciferase units over unstimulated cells. Relative luciferase activity is calculated as the ratio between the absolute caspase luminescent values normalized to cell vitality (Cell titer Glo, Promega). Data are expressed as the mean \pm S.D. of at least five experiments performed in triplicate.

siRNA assays. siRNA inhibition of caspase- 8 , caspase- 9 and Gadd $45 \alpha$ was carried out by using HP validated siRNA, all purchased from Qiagen (Milano, Italia): Hs_CASP8_11_HP validated SIRNA (NM_001228), Hs_CASP9_7_HP validated siRNA (NM_001229) and Hs_Gadd45 $\alpha$ _5_HP validated siRNA (NM_001924), respectively. Caspase-8 and caspase- 9 depletion was verified by western blot analysis with purified mouse anti-human caspase-8 monoclonal antibody (clone 3-1-9, BD Pharmingen, San José, CA, USA) and monoclonal anti-human caspase-9 (clone LAP6, R\&D System), respectively. A monoclonal anti- $\beta$-tubulin (clone TUB 2.1, Sigma-Aldrich) antibody was used as a control. Gadd45 $\alpha$ depletion was evaluated through RT-PCR (Supplementary Information Figure S3).

HeLa cells were transfected with $5 \mathrm{nM}$ double-stranded sRNA using HiPerfect transfection reagent (Qiagen) according to the manufacturer's protocol. For caspase-8 and caspase- 9 at $96 \mathrm{~h}$ after transfection, cells were infected in order to evaluate caspase- 3 activity, as detailed above. Otherwise, for Gadd $45 \alpha$ caspases' activity and TUNEL analysis were carried out in HeLa cells infected following $48 \mathrm{~h}$ from transfection.

Analysis of mitochondrial membrane potential. Evaluation of mitochondrial membrane potential $\left(\Delta \psi_{\mathrm{M}}\right)$ was carried out by flow cytometric analysis by staining infected and uninfected HeLa cells with mitochondrion-selective probe tetramethylrhodamine methyl ester (TMRM), as already reported. ${ }^{38}$ Uninfected cells treated for 45 min with $\mathrm{H}_{2} \mathrm{O}_{2}$ (Sigma-Aldrich) at the concentration of $5 \mathrm{mM}$, were the positive control. Briefly, infected cells were detached from dishes, washed once in phosphate-buffered saline (PBS) and re-suspended in $50 \mu \mathrm{l}$ HEPES buffer ( $10 \mathrm{mM}$ HEPES, $135 \mathrm{mM} \mathrm{NaCl}, 5 \mathrm{mM} \mathrm{CaCl}$ ). Samples were incubated for $15 \mathrm{~min}$ at $37^{\circ} \mathrm{C}$ in TMRM $(200 \mathrm{nM})$, freshly prepared from stock solution $10 \mathrm{mM}$ in DMSO. Value acquisition was carried out on a FACSCalibur cytometer, as reported above; analysis was performed with WinMDI software (WinMDi, Joseph Trotter, The Scripps Institute, Flow Cytometry Core Facility). Evaluation of apoptotic (caspase-3/TMRM)-infected HeLa cells was carried out by flow cytometric analysis by double staining infected and uninfected HeLa cells with TMRM and caspase-3, as above.

Immunofluorescence of caspase-8 and -9 activities. Caspase- 8 and caspase-9 maturation were also evaluated through fluorescence microscopy staining by using Carboxyfluorescein FLICA Apoptosis Detection kit Caspase assay (Immunochemistry Technologies, LLC, Bloomington, MN USA). Staining protocol was set up according to the manufacturer's instructions. At specified time points, infected HeLa monolayers were washed once in PBS, fixed for 10 min in $3,7 \%$ paraformaldheyde solution and incubated for $1 \mathrm{~h}$ at $37^{\circ} \mathrm{C}$ under $5 \% \mathrm{CO}_{2}$ in $1 \mathrm{X} \mathrm{FLICA}$ solution, freshly prepared from stock solution $30 \mathrm{X}$ in DMSO. Nuclei were stained for $3 \mathrm{~min}$ with $2 \mu \mathrm{g} / \mathrm{ml} 4^{\prime}-6$-diamidino-2-phenylindole (DAPI) solution. Uninfected cells and cells treated for $4 \mathrm{~h}$ with $2 \mu \mathrm{M}$ STP or alternatively for $12 \mathrm{~h}$ with $\mathrm{CHX}$ plus TNF$\alpha$, as above, were used as controls.

Stained cells were examined using a Leica DMRE microscope and images were recorded on Leica DC250 camera and processed using Qwin software (Leica Microsystems, Milano, Italia).

Microarray and real-time PCR. Expression level of pro- and anti-apoptotic genes in S. flexneri-infected HeLa monolayers was evaluated by using Dual Chip microarrays Human apoptosis kit (Eppendorf, Milano, Italia) as recommended by the manufacturer. Uninfected cells or HeLa cells infected at MOI 100 were processed after 1,3 and $5 \mathrm{~h}$ of incubation p.i. and total RNA was extracted by using RNeasy Plus Mini Kit (Qiagen). Approximately, $5 \mu \mathrm{g}$ of total RNA was used for biotin-dNTP cDNA synthesis and labeling, by using Superscript II Reverse 
Transcriptase (Invitrogen, Milano, Italia). Biotinylated cDNA was labeled by using Silverquant Detection Kit (Eppendorf), as recommended by the instructions. Hybridization protocol and washing steps were performed according to the manufacturer's suggestions. Image data acquisition and gene expression profiling analysis were carried out by applying Silverquant analysis software (Eppendorf) (Supplementary Information Table S1).

Quantitative real-time PCR (qPCR) and western blot analysis were applied to validate gene expression profiling. For qPCR $10 \mathrm{ng}$ of CDNA, from both uninfected and M90T-infected HeLa cells, was used in each reaction. QPCR was carried out in triplicate by using Power SYBR Green PCR Master Mix (Applied Biosystem, Monza, Italia), in $30 \mu$ reaction volume, by using a 7300 Real-Time PCR System (Applied Biosystem). The $2^{-\Delta \Delta C t}$ method was applied to analyze the relative changes in expression profiling of interest genes, as already reported. ${ }^{39}$ Values were normalized to the internal gapdh gene control. Primers for qPCR were designed through Primer Express software (Applied Biosystem) and are listed in Supplementary Information File S1.

Western blot. Total cell extracts were prepared at $4{ }^{\circ} \mathrm{C}$ in $135 \mathrm{mM} \mathrm{NaCl}, 20 \mathrm{mM}$ Tris- $\mathrm{HCl} \mathrm{pH} \mathrm{7.5,} 1 \mathrm{mM} \mathrm{CaCl} 2,1 \%$ Triton X-100 in the presence of phosphatase and protease inhibitors. Samples were then separated in reducing conditions on SDSpolyacrylamide gels and transferred onto Hybond-C Extra membranes (Amersham, Little Chalfont, UK). Primary antibodies were incubated $16 \mathrm{~h}$ at $4{ }^{\circ} \mathrm{C}$, and horseradish peroxidase-conjugated secondary antibodies were added for $1 \mathrm{~h}$. Proteins were visualized by enhanced chemiluminescence (Amersham). The goat polyclonal anti-actin antibody, the rabbit polyclonal anti-IAP1, anti- IAP2, anti-Bax, anti-Bad, anti-Gadd $45 \alpha$ antibodies were from Santa Cruz Biotechnology (Santa Cruz, CA, USA); the mouse monoclonal anti-Bcl-2 antibody was from Becton Dickinson Pharmingen (Franklin Lakes, NJ, USA); the rabbit monoclonal anti-Bcl- $\mathrm{X}_{\mathrm{L}}$ and the rabbit polyclonal anti-Akt antibodies were from Cell Signaling (Beverly, MA, USA).

EVOC model of infection. All patients are informed on admission that tissue samples or organs obtained during diagnostic or treatment procedures may be also used for research purposes, through an appropriate informed consent form approved by the Ethics Committee of the European Institute of Oncology (IEO).

The assay was performed in accordance to a protocol recently developed by Ktisilingiri et al. (submitted). Briefly, healthy colonic tissues were obtained from patients undergoing surgery for colon cancer. Collected tissue samples, maintained in Hank's balanced salt solution, were transported to the laboratory and processed within the next hours. Mucosa layer, separated from the underlying tissues, was then divided in pieces of about $1 \mathrm{~cm}^{2}$ and oriented mucosal surface upward on sterile metal grids. Cylinder was attached to the tissue on the top of the mucosa layer with the use of surgical glue. Then, the samples were put on to a center-well tissue culture petri dishes containing $1 \mathrm{ml}$ of medium. $100 \mu \mathrm{l}$ of bacterial logarithmic growth culture (approximately $1 \times 10^{8}$ bacteria) were added inside the cylinder and the petri dishes were incubated in $95 \% \mathrm{O}_{2}-5 \% \mathrm{CO}_{2}$ atmosphere inside an airtight container at $37^{\circ} \mathrm{C}$ for $12 \mathrm{~h}$. Following incubation, colonic-infected tissues were fixed in $4 \%$ paraformaldeyde and processed for histological and $\mathrm{IH}$ analyses. As a routinely procedure, EVOC tissue sections were first immunostained with an anti-Ki$67 \mathrm{mAb}$, which is a marker for cell proliferation. Only samples showing a positive reaction for the presence of this protein were processed for further histopathological and $\mathrm{IH}$ studies.

Immunohistological studies. Samples for histological and $\mathrm{IH}$ analysis were fixed in $10 \%$ buffered formalin and paraffin embedded. Three-micrometer-thick sections were stained with $\mathrm{HE}$ stain for histopathological examination. For $\mathrm{IH}$ tests, sections were treated as previously reported. ${ }^{21}$ Briefly, to localize S. flexneri antigen in infected tissues and to characterize immunohistochemically the apoptosis and related molecules in epithelial/inflammatory cell populations the following antibodies were used on serial sections: rabbit polyclonal anti-Shigella flexneri 5a LPS, rabbit pAb anti-Gadd $45 \alpha$ (1:50, Millipore Corporate Headquarters, Billerica, MA, USA), rabbit pAb anti-cleaved caspase-3 $(1: 10$, anti-active caspase-3 pAb, Promega Corporation). In particular, expression of cleaved caspase-3 was investigated using an affinity-purified rabbit polyclonal antibody directed against a peptide from the p18 fragment of the cleaved human caspase- 3 and evaluated as suggested by Resendes et al..$^{40}$ Antibody-binding was revealed through $A B C$-peroxydase or $A B C$ - alkaline phosphatase techniques using $1: 200$ diluted biotin conjugated goat-anti rabbit immunoglobulin G (Vector Laboratories, Inc., Burlingame, CA, USA) and a $1: 200$ diluted biotinylated goat-anti mouse Ig (AO433; DAKO, Glostrup, Denmark), applied for $45 \mathrm{~min}$ at room temperature as secondary antibodies. The enzymatic reaction was developed with 3-1-diaminobenzydine (DAB, with/without nichel) (Sigma Chemical Co., St. Louis, MO, USA) or VIP (Vector) as substrates. For all antibodies used, the primary antibody was replaced by PBS as a negative control.

In colonic sections apoptotic index in epithelial and inflammatory cells was highlighted through a TUNEL colorimetric staining (DeadEnd, Promega) according to the manufacturer's instructions.

To score the consistence of Gadd $45 \alpha$, caspase-3 and TUNEL-positive cells in M90T- and BS176-infected and uninfected samples, five random fields of the sample were examined under a dry-X40 objective. The number of epithelial-positive cells was normalized to the number of epithelial cells per field.

Statisticals. Data were presented as mean \pm S.D., and the numbers of independent experiments were indicated in each legend of the figures. Statistical calculations and tests were performed using the Student's t-test. A $P$-value $<0.05$ was considered statistically significant. A $P$-value $<0.001$ was considered extremely significant.

\section{Conflict of Interest}

The authors declare no conflict of interest.

Acknowledgements. This work was partially supported by grants from the Italian 'Ministero dell'Istruzione, Università e Ricerca' (PRIN 2009). Luigi LemboFazio, Giulia Nigro and Gaëlle Noël were fellows of the 'Istituto Pasteur-Fondazione Cenci Bolognetti'. Katerina Tsilingiri is a recipient of a Marie-Curie fellowship within the cross-talk network.

1. Labbe K, Saleh M. Cell death in the host response to infection. Cell Death Differ 2008; 15 : 1339-1349.

2. Deretic V, Levine B. Autophagy, immunity, and microbial adaptations. Cell Host Microbe 2009; 5: 527-549.

3. Mathan VI, Mathan MM. Intestinal manifestations of invasive diarrheas and their diagnosis. Rev Infect Dis 1991; 13 (Suppl 4): S311-S313.

4. Sansonetti PJ, Ryter A, Clerc P, Maurelli AT, Mounier J. Multiplication of Shigella flexneri within HeLa cells: Iysis of the phagocytic vacuole and plasmid-mediated contact hemolysis. Infect Immun 1996; 51: 461-469.

5. Parsot C. Shigella flexneri: genetics of entry and intercellular dissemination in epithelial cells. Curr Top Microbiol Immunol 1994; 192: 217-241.

6. Girardin SE, Boneca IG, Carneiro LA, Antignac A, Jehanno M, Viala J et al. Nod1 detects a unique muropeptide from gram-negative bacterial peptidoglycan. Science 2003; 300: 1584-1587.

7. Suzuki T, Franchi L, Toma C, Ashida H, Ogawa M, Yoshikawa $Y$ et al. Differential regulation of caspase-1 activation, pyroptosis, and autophagy via Ipaf and ASC in Shigella-infected macrophages. PLoS Pathog 2007; 3: e111.

8. Hilbi H, Chen Y, Thirumalai K, Zychlinsky A. The interleukin 1beta-converting enzyme, caspase 1 , is activated during Shigella flexneri-induced apoptosis in human monocytederived macrophages. Infect Immun 1997; 65: 5165-5170.

9. Koterski JF, Nahvi M, Venkatesan MM, Haimovich B. Virulent Shigella flexneri causes damage to mitochondria and triggers necrosis in infected human monocyte-derived macrophages. Infect Immun 2005; 73: 504-513.

10. Nonaka T, Kuwae A, Sasakawa C, Imajoh-Ohmi S. Shigella flexneri YSH6000 induces two types of cell death, apoptosis and oncosis, in the differentiated human monoblastic cell line U937. FEMS Microbiol Lett 1999; 174: 89-95.

11. Suzuki T, Nakanishi K, Tsutsui H, Iwai H, Akira S, Inohara N et al. A novel caspase-1/tolllike receptor 4-independent pathway of cell death induced by cytosolic Shigella in infected macrophages. J Biol Chem 2005; 280: 14042-14050.

12. Carneiro LA, Travassos LH, Soares F, Tattoli I, Magalhaes JG, Bozza MT et al. Shigella induces mitochondrial dysfunction and cell death in nonmyleoid cells. Cell Host Microbe 2009; 5: 123-136.

13. Faherty CS, Maurelli AT. Spa15 of Shigella flexneri is secreted through the type III secretion system and prevents staurosporine-induced apoptosis. Infect Immun 2009; 77: $5281-5290$.

14. Tattoli I, Lembo-Fazio L, Nigro G, Carneiro LA, Ferraro E, Rossi G et al. Intracellular bacteriolysis triggers a massive apoptotic cell death in Shigella-infected epithelial cells. Microbes Infect 2008; 10: 1114-1123.

15. Cersini A, Salvia AM, Bernardini ML. Intracellular multiplication and virulence of Shigella flexneri auxotrophic mutants. Infect Immun 1998; 66: 549-557.

16. Dupont N, Lacas-Gervais S, Bertout J, Paz I, Freche B, Van Nhieu GT et al. Shigella phagocytic vacuolar membrane remnants participate in the cellular response to pathogen invasion and are regulated by autophagy. Cell Host Microbe 2009; 6: 137-149. 
17. Gao M, Guo N, Huang C, Song L. Diverse roles of GADD45alpha in stress signaling. Curr Protein Pept Sci 2009; 10: 388-394.

18. Tong T, Ji J, Jin S, Li X, Fan W, Song $Y$ et al. Gadd45 $\alpha$ expression induces Bim dissociation from the cytoskeleton and translocation to mitochondria. Mol Cell Biol 2005; 25: 4488-4500.

19. Li Y, Qian H, Li X, Wang H, Yu J, Liu Y et al. Adenoviral-mediated gene transfer of Gadd45 $\alpha$ results in suppression by inducing apoptosis and cell cycle arrest in pancreatic cancer cell. J Gene Med 2009; 11: 3-13.

20. Zerbini LF, Wang Y, Czibere A, Correa RG, Cho JY, ljiri K et al. NF-kappa B-mediated repression of growth arrest- and DNA-damage-inducible proteins 45alpha and gamma is essential for cancer cell survival. Proc Natl Acad Sci USA 2004; 101: 13618-13623.

21. Martino MC, Rossi G, Martini I, Tattoli I, Chiavolini D, Phalipon A et al. Mucosal lymphoid infiltrate dominates colonic pathological changes in murine experimental shigellosis. $J$ Infect Dis 2005; 192: 136-148.

22. O'Reilly MA, Staversky RJ, Watkins RH, Maniscalco WM, Keng PC. p53-independent induction of GADD45 and GADD153 in mouse lungs exposed to hyperoxia. Am J Physiol Lung Cell Mol Physiol 2003; 278: L552-L559.

23. Rudel T, Kepp O, Kozjak-Pavlovic V. Interactions between bacterial pathogens and mitochondrial cell death pathways. Nat Rev Microbiol 2010; 8: 693-705.

24. Srinivasula SM, Ashwell JD. IAPs: what's in a name? Mol Cell 2008; 30: 123-135.

25. Downward J. PI 3-kinase, Akt and cell survival. Semin Cell Dev Biol 2004; 15: 177-182.

26. Pedron T, Thibault C, Sansonetti PJ. The invasive phenotype of Shigella flexneri directs a distinct gene expression pattern in the human intestinal epithelial cell line Caco-2. J Biol Chem 2003; 278: 33878-33886.

27. Pendaries C, Tronchere H, Arbibe L, Mounier J, Gozani O, Cantley L et al. Ptdlns5P activates the host cell PI3-kinase/Akt pathway during Shigella flexneri infection. Embo J 2006; 25: 1024-1034.

28. Chipuk JE, Moldoveanu T, Llambi F, Parsons MJ, Green DR. The BCL-2 family reunion. Mol Cell 2010; 37: 299-310.

29. Rasola A, Sciacovelli M, Pantic B, Bernardi P. Signal transduction to the permeability transition pore. FEBS Lett 2010; 584: 1989-1996.

30. Gramaglia D, Gentile A, Battaglia M, Ranzato L, Petronilli V, Fassetta M et al. Apoptosis to necrosis switching downstream of apoptosome formation requires inhibition of both glycolysis and oxidative phosphorylation in a BCL-X(L)- and PKB/AKT-independent fashion. Cell Death Differ 2004; 11: 342-353.

31. Nicotera P, Melino G. Regulation of the apoptosis-necrosis switch. Oncogene 2004; 23 2757-2765.

32. Orrenius S, Zhivotovsky B, Nicotera P. Regulation of cell death: the calcium-apoptosis link Nat Rev Mol Cell Biol 2003; 4: 552-565.

33. Rasola A, Bernardi $P$. The mitochondrial permeability transition pore and its involvement in cell death and in disease pathogenesis. Apoptosis 2007; 12: 815-833.

34. Rosemary Siafakas A, Richardson DR. Growth arrest and DNA damage-45 alpha (GADD45alpha). Int J Biochem Cell Biol 2009; 41: 986-989.

35. Hoffman B, Liebermann DA. Gadd45 modulation of intrinsic and extrinsic stress responses in myeloid cells. J Cell Physiol 2009; 218: 26-31.

36. Hasegawa Y, Mans JJ, Mao S, Lopez MC, Baker HV, Handfield M et al. Gingival epithelial cell transcriptional responses to commensal and opportunistic oral microbial species. Infect Immun 2007; 75: 2540-2547.

37. Martinoli C, Chiavelli A, Rescigno M. Entry route of Salmonella typhimurium directs the type of induced immune response. Immunity 2007; 27: 975-984.

38. Rasola A, Geuna M. A flow cytometry assay simultaneously detects independent apoptotic parameters. Cytometry 2001; 45: 151-157.

39. Livak KJ, Schmittgen TD. Analysis of relative gene expression data using real-time quantitative PCR and the 2(-Delta Delta C(T)). Methods 2001; 25: 402-408.

40. Resendes AR, Majo N, Segales J, Espadamala J, Mateu E, Chianini F et al. Apoptosis in normal lymphoid organs from healthy normal, conventional pigs at different ages detected by TUNEL and cleaved caspase-3 immunohistochemistry in paraffin-embedded tissues. Vet Immunol Immunopathol 2004; 99: 203-213.

Cell Death and Disease is an open-access journal published by Nature Publishing Group. This work is licensed under the Creative Commons Attribution-Noncommercial-No Derivative Works 3.0 Unported License. To view a copy of this license, visit http://creativecommons.org/licenses/by-nc-nd/3.0/

\section{Supplementary Information accompanies the paper on Cell Death and Disease website (http://www.nature.com/cddis)}

